\title{
Spleen Preservation in Laparoscopic Distal Pancreatectomy for Solitary Pseudopapillary Tumors Is Oncologic Safe
}

\author{
Seog Ki Min, M.D., Ph.D. \\ Division of Hepatobiliary-Pancreas Surgery, Department of Surgery, Ewha Womans University Seoul Hospital, Ewha Womans Universiy College of Medicine, \\ Seoul, Korea
}

\begin{abstract}
Pancreatic solid pseudopapillary neoplasm (SPN) is a rare tumor that is mostly benign, but a surgical resection is recommended. Pancreatic SPN has a relatively well-demarcated margin and lymph node metastases are rare. The prognosis of pancreatic SPN is relatively good. Therefore, minimally invasive surgery (MIS) is often available. When a distal pancreatectomy is performed for SPN located at the pancreatic body or tail, it is believed to preserve the spleen. MIS with preservation of spleen not only helps the patient recover after surgery, but also does not worsen the oncology results compared to open surgery with or without a splenectomy. Recently, robotic surgery has expanded gradually. Therefore, it is expected that MIS with spleen preservation will become more common for pancreatic SPN.
\end{abstract}

Keywords: Pancreatic neoplasm, Laparoscopy, Pancreatectomy, Spleen, Organ preservation

\author{
Received February 19, 2019 \\ Accepted March 5, 2019 \\ Corresponding author \\ Seog Ki Min \\ Division of Hepatobiliary-Pancreas \\ Surgery, Department of Surgery, \\ Ewha Womans University Seoul \\ Hospital, Ewha Womans Universiy \\ College of Medicine, 260 Gonhang- \\ daero, Gangseo-gu, Seoul 07804, \\ Korea \\ Tel: $+82-2-6986-1646$ \\ Fax: +82-2-2644-7984 \\ E-mail:mp9666@ewha.ac.kr \\ ORCID: \\ http://orcid.org/0000-0001-9894-7603
}

Copyright $\odot 2019$ The Journal of Minimally Invasive Surgery. All rights reserved.
This is an Open Access article distributed under the terms of the Creative Commons Attribution Non-Commercial License (http:// creativecommons.org/licenses/by-nc/4.0/) which permits unrestricted non-commercial use, distribution, and reproduction in any medium, provided the original work is properly cited.
A solid pseudopapillary neoplasm (SPN) is relatively rare in pancreatic tumors and has been reported in approximately 1 2\% of pancreatic tumor cases. ${ }^{1,2}$ Most cases have a benign nature, but approximately 9 15\% are malignant with local invasion or metastasis. ${ }^{3,4}$ Therefore, surgical resection is recommended if possible if a pancreatic tumor is suspected or diagnosed as SPN, and the prognosis is relative good after an appropriate resection of the primary lesion. Overall, the 5-year survival rate has been reported to be approximately $97 \%$. ${ }^{5} \mathrm{SPN}$ is variable in size and may be as large as $10 \mathrm{~cm}$. In most cases, however, direct adhesion to the adjacent tissues or organs is rare, except for malignancies with local invasion. Therefore, when performing a pancreatectomy with SPN, it is generally more convenient to access than pancreatic cancer or pancreatitis surgery. If the distal pancreatectomy is considered in SPN, it is possible to perform minimally invasive surgery, including laparoscopic surgery, as well as conventional open surgery. In the treatment of intraperitoneal cancer, minimally invasive surgery, such as laparoscopic surgery, has been shown to be equivalent or superior to conventional open surgery in terms of the oncologic results. ${ }^{6}$ Because of the advantages of minimally invasive surgery, it should be considered as a priority to decide the treatment for SPN. Compared to open surgery, it is necessary to confirm precisely the pre-operative metastasis because it is difficult to identify the complete intraabdominal organs at the time of surgery for minimally in- 
vasive surgery. According to a recent multicenter study, up to $29 \%$ of cases with metastatic disease have been reported in aggressive cases at the time of diagnosis. ${ }^{7}$ Despite the metastasis of malignant cases, lymph node metastasis is relatively rare, and spleen preservation in a pancreatectomy has been shown to reduce severe infections or complications after surgery compared to a resection, including splenic involvement. ${ }^{8}$ Therefore, it is best to preserve the spleen as much as possible if there is no difference in oncologic safety. These authors successfully performed a splenic resection and splenic preservation in both groups and reported excellent results. The technical problems can be overcome if experience is gained. Moreover, minimally invasive surgery and splenic preservation is strongly recommended in the initial treatment options for SPN. Recently, delicate surgery, including a pancreatectomy, has been another turning point with the introduction of robot surgery. ${ }^{9,10}$ Surgeons can overcome much of the difficulty of laparoscopic pancreatectomy with or without preserving the spleen using a robot system, which would allow a complete resection of the tumor with a partial pancreas and complete preservation of the spleen with the vessels and adjacent normal tissues. This procedure would be expected to minimize the postoperative complications. In the future, this minimally invasive surgical procedure and preservation of the spleen or surrounding organs are expected to be expanded further in SPN treatments.

\section{REFERENCES}

1) Martin RC, Klimstra DS, Brennan MF, Conlon KC. Solid-pseudopapillary tumor of the pancreas: a surgical enigma? Ann Surg Oncol 2002;9:35-40.

2) Naar L, Spanomichou DA, Mastoraki A, Smyrniotis V, Arkado- poulos N. Solid Pseudopapillary Neoplasms of the Pancreas: A Surgical and Genetic Enigma. World J Surg 2017;41:1871-1881.

3) Reddy S, Cameron JL, Scudiere J, et al. Surgical management of solid-pseudopapillary neoplasms of the pancreas (Franz or Hamoudi tumors): a large single-institutional series. J Am Coll Surg 2009;208:950-957; discussion 957-959.

4) Law JK, Ahmed A, Singh VK, et al. A systematic review of solidpseudopapillary neoplasms: are these rare lesions? Pancreas 2014;43:331-337.

5) Pokrzywa CJ, Abbott DE, Matkowskyj KA, et al. Natural History and Treatment Trends in Pancreatic Cancer Subtypes. J Gastrointest Surg 2019 Jan 31 [Epub]. DOI:10.1007/s11605-019-04113-3.

6) Castaing D, Vibert E, Ricca L, Azoulay D, Adam R, Gayet B. Oncologic results of laparoscopic versus open hepatectomy for colorectal liver metastases in two specialized centers. Ann Surg 2009;250:849-855.

7) Hao EIU, Hwang HK, Yoon DS, Lee WJ, Kang CM. Aggressiveness of solid pseudopapillary neoplasm of the pancreas: A literature review and meta-analysis. Medicine (Baltimore) 2018;97:e13147.

8) Milito P, Aiolfi A, Asti E, Rausa E, Bonitta G, Bonavina L. Impact of Spleen Preserving Laparoscopic Distal Pancreatectomy on Postoperative Infectious Complications: Systematic Review and Meta-Analysis. J Laparoendosc Adv Surg Tech A 2019;29:167177.

9) Kim SH, Kang CM, Lee WJ. Robotic single-site plus ONE port distal pancreatectomy. Surg Endosc 2017;31:4258-4259.

10) Lalli R, Merritt N, Schlachta CM, Butter A. Robotic-assisted, spleen-preserving distal pancreatectomy for a solid pseudopapillary tumour in a pediatric patient: a case report and review of the literature. J Robot Surg 2018 Jun 8 [Epub]. DOI:10.1007/s11701018-0835-0. 